\title{
The Use of Honeybee Hives May Boost Yields of Some Crops in Nepal
}

\author{
Kedar Devkota $\mathbb{D}$, ${ }^{1,2}$ Prashant Rijal $\mathbb{D}^{2},{ }^{2}$ and Charles Fernando dos Santos $\mathbb{D}^{3}$ \\ ${ }^{1}$ Faculty of Agriculture, Agricultural and Forestry University, Rampur, Chitwan, Nepal \\ ${ }^{2}$ Institute of Agriculture and Animal Science, Kathmandu, Nepal \\ ${ }^{3}$ School of Health and Life Sciences, Pontifical Catholic University of Rio Grande do Sul, Ipiranga Avenue 6681, \\ 90619-900 Porto Alegre, RS, Brazil \\ Correspondence should be addressed to Kedar Devkota; kdevkota@afu.edu.np
}

Received 14 April 2020; Revised 8 November 2021; Accepted 1 December 2021; Published 14 December 2021

Academic Editor: David Roubik

Copyright ( 2021 Kedar Devkota et al. This is an open access article distributed under the Creative Commons Attribution License, which permits unrestricted use, distribution, and reproduction in any medium, provided the original work is properly cited.

\begin{abstract}
Many pollination-dependent crops worldwide need bees for the highest productivity. If the crops are not pollinated, a pollination deficit will result. Consequently, low yields of fruit set and seed set of cultivated plants may be expected. Here, we evaluated how pollination with honeybee (Apis mellifera) hives may affect the production of the bittergourd (Momordica charantia), buckwheat (Fagopyrum esculentum), and mustard (Brassica campestris) in tons or quintal per hectare in Nepal. Our experimental design involved three treatments in blocks within selected areas: (i) the effect of the honeybees alone (caged with beehives), (ii) free insect access under natural field conditions, and (iii) blocks restraining insect access (caged without beehives). We also assessed the flower visiting insects within crops using pan traps and identifying insect orders. We found that the productivity of bittergourd, buckwheat, and mustard significantly increased in the treatments with beehives inside the cage. To a lesser extent, the treatment with free access to the flying insects enhanced the production of the selected crops. Proportionally, Hymenoptera (mainly bees) was the most common taxon within bittergourd, buckwheat, and mustard crops, followed by Diptera and Lepidoptera. Hence, the provision of beehives in cultivated areas such as those evaluated here could be considered as a complementary strategy for supporting the long-term productivity of these crops in Nepal.
\end{abstract}

\section{Introduction}

The ecosystem service of pollination, commonly mediated by animals, may considerably increase the production of more than $70 \%$ of the agricultural crops cultivated in the world $[1,2]$. Pollination services in both wild and cultivated plants are primarily provided not only by bees [3] but also by other taxa of floral visitors [4]. Bees assume more relevance in pollination due to their necessity of nourishment based on pollen and nectar as well as by using plants as nesting sites [5]. Pollination is essential for ecosystem functioning since it contributes to the maintenance of plant diversity [6]. It also provides an economically important service to humans, contributing ca. USD \$235-577 billion in annual crop production globally [7].
Declines in pollinator populations may affect the pollination services [8], which may cause direct impacts on crop production, food security, and human welfare $[2,3]$. Such a reduction in pollinator populations raises the question of the specific dependency of different crops on insect pollination and whether current pollinator communities fulfill the levels of pollination required for yield maximization [9].

Since there exists an increase in the demand for pollination services within crop fields and a corresponding decline in pollinator diversity [10], managed pollinators could be an alternative to increase the productivity of agricultural crops [7]. Among the managed pollinators, honeybees are capable of increasing the yield of many crops $[1,11]$. For example, managed honeybees, Apis mellifera L. (Hymenoptera: Apidae), were found to visit more than 
half of the cultivated crops in Europe [12]. Pollination services provided by honeybees can increase crop yields, as well as generate income through the sale of bee products, contributing to more sustainable livelihoods [13].

In Nepal, some crops have broad economic and public interest. For example, bittergourd (Momordica charantia: Cucurbitaceae) is one of the most famous cucurbit crops in the Asian region and is highly dependent on bee pollination [14]. Buckwheat (Fagopyrum esculentum: Polygonaceae) is also a very important underutilized, highly pollinator-dependent crop whose yields may be increased with bee pollination [15]. Similarly, mustard (Brassica campestris var. toria: Brassicaceae) crops are the most essential oilseed crops grown in Nepal. The production of mustard increases with the pollination services provided by honeybees [13].

Here, we aimed to assess the effect of A. mellifera, managed honeybees, on the yields of bittergourd, buckwheat, and mustard. More specifically, (i) we analyzed the individual effect of $A$. mellifera hives in isolation from other insects (ii) as compared with treatments in which flying insects were allowed under natural field conditions and (iii) with treatments excluding all flying insects. Thus, the yields of each crop (bittergourd, buckwheat, and mustard) were compared according to their corresponding treatment.

The fruit weight and seed weight (= the yield harvested per unit area) were used as a proxy for crop yields, following the work of Garibaldi et al. [3]. Furthermore, we recorded the abundance of major insect orders present in the immediate vicinity of the three targeted crops. We hypothesized that bittergourd, buckwheat, and mustard crops exposed to A. mellifera colonies would show higher yields than crops under natural pollination conditions or pollinator exclusion.

\section{Materials and Methods}

2.1. Study Sites. The research was carried out in the Chitwan district of Nepal, during 2015 and 2016. Bittergourd, buckwheat, and mustard were the targeted crops as they are widely cultivated in different parts of these districts. The research on bittergourd was conducted in Fulbari and Gitanagar (mid-Chitwan); buckwheat in Meghauli (western Chitwan); and mustard in Padampur and Jutpani (eastern Chitwan). For each crop, we selected five fields with a minimum distance of $2 \mathrm{~km}$ between them to avoid pseudoreplication. Bittergourd fields were at least 2 kattha (0.06 ha) in size whereas as in buckwheat and mustard, we established a study area of $50 * 25 \mathrm{~m}$ [16] in the respective sites of the crops.

2.2. Experimental Design and Yield Analysis. We established a block experiment in each of the five fields ( $5=$ bittergourd; $5=$ buckwheat; and $5=$ mustard). Within each block, there were three treatments of $15 \mathrm{~m}^{2}$ area: (i) open pollination by the natural pollinator community; (ii) control (excluding all flower visitors); and (iii) pollination by honeybees only (wild pollinators excluded). In treatments 2 and 3, wild insects were excluded from visiting flowers by a nylon mosquito net cage. In treatment 3, a two-frame A. mellifera beehive was included within the cage to provide high densities of honeybees, whilst excluding all other flower visitors. In bittergourd crops, whole plants within the area of $15 \mathrm{~m}^{2}$ were assessed for the yield, whereas in buckwheat and mustard crops, we harvested a $1 \mathrm{~m}^{2}$ area subsample to assess the yields.

We installed the nylon nets, covering an area of $15 \mathrm{~m}^{2}$, before the onset of flowering. As soon as flowers had wilted, we removed the nets, and tagged plants were left to ripen in the field until harvest. Additionally, while buckwheat and mustard yields were measured as a quintal (1/10 of ton) per hectare, and bittergourd was measured as a ton per hectare since these units are a commonplace in Nepal for the three target crops.

2.3. Insect Sampling. To assess the abundance of potential floral visitors, we used pan traps with three different colors, yellow, white, and blue. These represented prevailing floral colors in the study regions accounting for different color preferences of insect species $[17,18]$. The 24 ( 8 of each color) pan traps were set $5 \mathrm{~m}$ apart within the selected crops, and they were located such that each bowl was not hidden by vegetation but left out in the open where they were visible to bees.

In this study, we placed the pan traps on the ground within all crop fields and left them for 24 hours per sampling. After each sampling round, the pan traps were removed from the study sites and specimens were collected. The collected specimens were taxonomically differentiated to the major taxa, including bees (Hymenoptera: Anthophila), hoverflies (Diptera: Syrphidae), and butterflies (Lepidoptera). It is necessary to highlight, however, that pan traps may undersample butterfly diversity, a potential limitation of this sampling procedure. We visited each crop three times during the flowering period of the targeted crops. The flowering period for buckwheat and mustard was between February-March 2015, while for bittergourd, the visits occurred in November 2016 being sampled weekly after the onset of blossoming.

2.4. Data Analysis. We investigated how relevant honeybees are to bittergourd, buckwheat, and mustard production (tons or quintal per hectare) comparing three treatments: (i) free access; (ii) restrained (netted) access; and (iii) honeybees only. We performed a generalized linear model (GLM) for each crop with a Gaussian family distribution. This analysis was performed using the function "glm" in $\mathrm{R}$, and parameters were extracted with the function Anova from package car [19]. After that, we performed multiple post hoc comparisons between each treatment within a specific crop. For this, we used a function for general linear hypotheses "glht" with Tukey's two-sided test from package multcomp [20]. The $p$ values were adjusted by controlling the false discovery rate $(\operatorname{method}=f \mathrm{~d} r$ ), the expected proportion of false discoveries amongst the rejected hypotheses. All analyses were carried out in R-software [21, 22]. 
TABLE 1: Results of the generalized linear model for yields of three crops in Nepal according to three experiments performed in bittergourd, buckwheat, and mustard fields.

\begin{tabular}{|c|c|}
\hline \multicolumn{2}{|l|}{ Bittergourd $(\mathrm{AIC}=60.43)$} \\
\hline & Average yields (tons/ha); overall mean 20.12 \\
\hline Control & $2.17 \pm 0.56$ \\
\hline Honeybee hives & $31.61 \pm 2.22$ \\
\hline Open access & $\begin{array}{c}26.56 \pm 1.40 \\
p \text { value }\end{array}$ \\
\hline Honeybee hives $\times$ control $==0$ & $<0.001$ \\
\hline Open access $\times$ control $==0$ & $<0.001$ \\
\hline Open access $\times$ honeybee hives $==0$ & $<0.001$ \\
\hline \multicolumn{2}{|l|}{ Buckwheat $(\mathrm{AIC}=43.72)$} \\
\hline & Average yields (quintal/ha); overall mean 6.60 \\
\hline Control & $3.38 \pm 0.93$ \\
\hline Honeybee hives & $9.08 \pm 0.99$ \\
\hline Open access & $6.87 \pm 0.70$ \\
\hline & $p$ value \\
\hline Honeybee hives $\times$ control $==0$ & $<0.001$ \\
\hline Open access $\times$ control $==0$ & $<0.001$ \\
\hline Open access $\times$ honeybee hives $==0$ & $<0.01$ \\
\hline \multicolumn{2}{|l|}{ Mustard $(\mathrm{AIC}=32.55)$} \\
\hline & Average yields (quintal/ha); overall mean 6.81 \\
\hline Control & $5.52 \pm 0.46$ \\
\hline Honeybee hives & $7.90 \pm 0.61$ \\
\hline Open access & $7.02 \pm 0.72$ \\
\hline & $p$ value \\
\hline Honeybee hives $\times$ control $==0$ & $<0.001$ \\
\hline Open access $\times$ control $==0$ & $<0.001$ \\
\hline Open access $\times$ honeybee hives $==0$ & 0.02 \\
\hline
\end{tabular}

AIC means the Akaike criterion information. In average yields, the production is shown as mean \pm standard deviation.

\section{Results}

We found significant differences among all treatments from all three crops related to their productivity in tons (GLM $_{\text {bittergourd, }} \quad \mathrm{LR}=1027, \quad$ d.f. $=2, \quad p$ value $<0.001$; $\mathrm{GLM}_{\text {buckwheat, }} \mathrm{LR}=87.7$, d.f. $=2, p$ value $<0.001$; and $\mathrm{GLM}_{\text {mustard }}, \mathrm{LR}=38.6$, d.f. $=2$, $p$ value $\left.<0.001\right)($ Table 1$)$. We also found that all pairwise comparisons were significantly different from each other, as shown in Table 1. It showed that yields of bittergourd, buckwheat, and mustard differed depending on whether they were caged to restrict all insect access or, if wild insects in the natural condition were present, or if $A$. mellifera beehives were put inside the cages. Overall, the placement of $A$. mellifera beehives within caged crops showed the highest yields amongst all crops (Figure 1).

Our data show that Hymenoptera were the most abundant flying insects in the vicinity of flowering target crops, followed by Diptera (Figure 2) and Lepidoptera $<9 \%$ (Figure 2). When we compare the abundance of all insects in the vicinity of the three crops, we can see that fewer insects were present around buckwheat 28\% (Figure 2). By contrast, bittergourd (32.1\%) and mustard (40\%) had a higher number of insects in their vicinity (Figure 2).

\section{Discussion}

In our study, we found that the yields (fruit set and seed set) of bittergourd, buckwheat, and mustard exposed to high densities of $A$. mellifera were higher than crops under natural pollination conditions, suggesting the presence of natural pollination deficits. Therefore, supplementing natural pollination services with honeybee hives could be considered as a valuable strategy to reduce pollination deficits and raise the productivity of these crops in Nepal. Even though this work did not specifically evaluate natural pollination in combination with supplementary honeybee hives, we can conclude that the presence of honeybee hives is likely to complement existing pollination services and help to close yield gaps. Indeed, it is well known from the literature that some crops need native bees foraging together with honeybees for better pollination services [3] and that placing beehives inside agricultural systems can improve yields in many crops [23]. The supplementation with hives of honeybees to improve outputs into three crops here may be seen as positive since most beneficial insects may be affected by various harmful practices adopted in the agricultural fields [24-26]. Elsewhere, pollination by honeybees increases the yield of the highly commercial crops and fruit trees such as sunflower, apple, peach, kiwifruit, citrus, and strawberry [27-29]. Additionally, it is well established that honeybees are effective pollinators in these three crops in Nepal [30] and contribute to higher yields of the mustard crops [31, 32] and buckwheat [15].

We observed that a large proportion of insects in the vicinity of these three crops were Hymenoptera, in particular bees. It is known that, within crops, it is common that bees are abundant in such agricultural areas [26, 32-34]. However, we also recorded other insect orders such as Diptera 


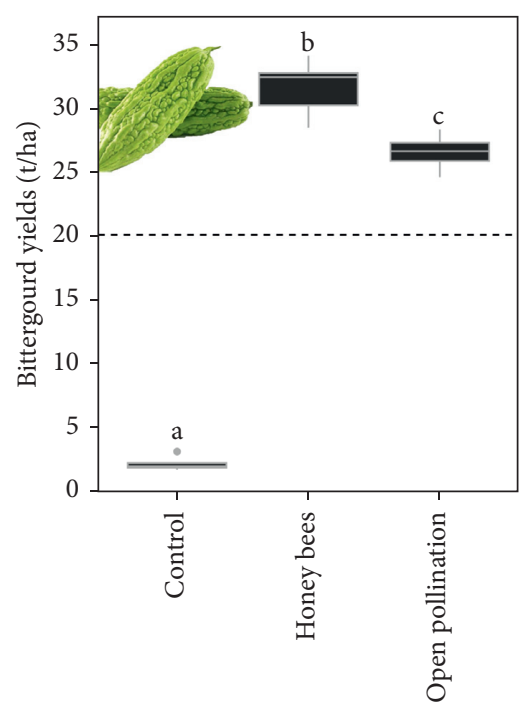

(a)

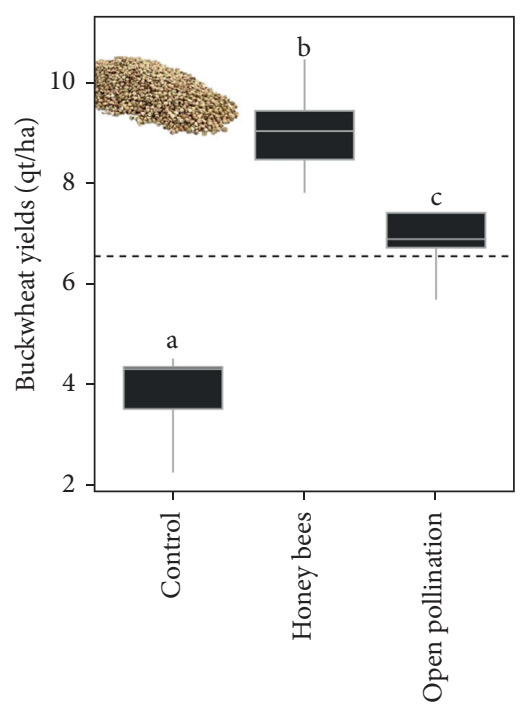

(b)

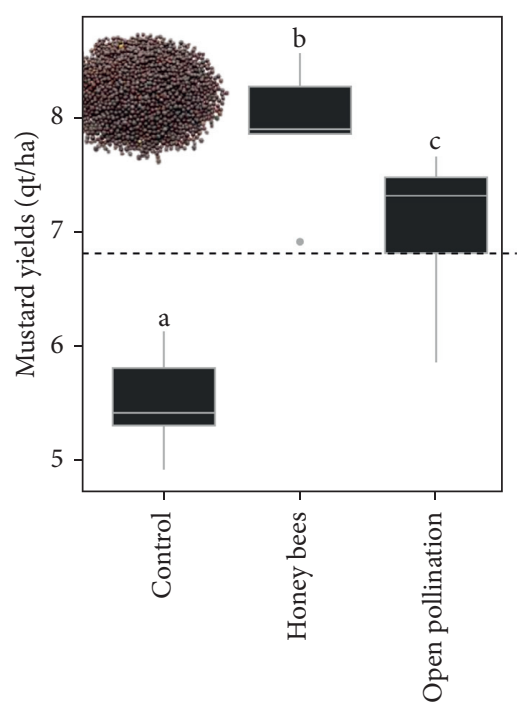

(c)

Figure 1: Production of bittergourd, buckwheat, and mustard crops in Nepal. Control=excluding all flower visitors; honeybee hives = adding Apis mellifera beehives; ans open access to insect = flowers freely accessible to any foraging insect. Note. Different letters over boxes indicate a significant difference at a low $\alpha$-level of 0.05 ; dashed lines in plots show the average production for every crop: bitter gourd (20.12 tons/ha), buckwheat (6.60 quintal/ha), and mustard (6.81 quintal/ha); and a ton is a tenth of quintal unit.

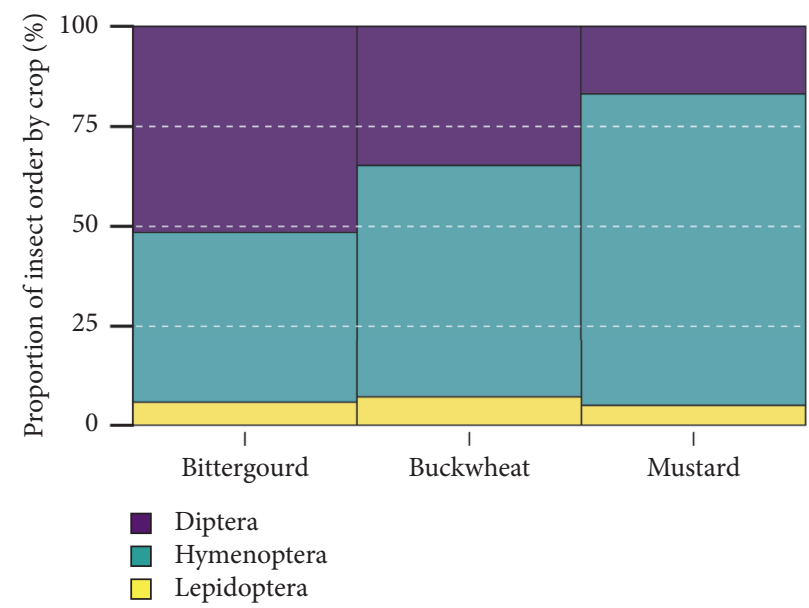

Figure 2: Proportion of the three insect orders (Diptera, Hymenoptera, Lepidoptera) sampled during open-access experiments within bittergourd, buckwheat, and mustard crops in Nepal. These orders include important pollinating groups as hoverflies, bees, and butterflies. Horizonal and white dashed lines were added every $25 \%$ to facilitate interpretation.

and Lepidoptera in our study areas. Although they were represented in a lower numbers, we cannot ignore that they may provide a complementary role in the pollination of bittergourd, buckwheat, and mustard if they offer this ecological service as the bees do [33, 35-37].

Depending on the situation, the farmers may face the problem of how to enhance the productivity within their crop fields. The maintenance of forest remnants $[26,34,38,39]$ and beekeeping can play relevant roles [13]. For example, the concept of integrated crop pollination (ICP) combines different pollinator-friendly strategies along with beekeeping to ensure stable and sustainable yields of pollination-dependent crops. Another possibility, as indicated in our study, could be to supply beehives to improve different crops as this practice seems to benefit yields $[23,40]$. The management of honeybees can occur over a wide distance and across the growing season because the beehive movements can take place for greater distances with a minimum cost of operation [41, 42]. In addition, we can handle beehives per hectare as required to provide a broad or the maximum flying coverage to crop fields demanding these insects [41].

Cultivated plants worldwide have different demands for beneficial insects such as bees to increase their productivity $[42,43]$. However, here, we offer strong support to farmers when they are facing doubts on whether and how to overcome complicated tasks such as choosing which strategies to apply to increase and foster higher productivity. In 
other words, we demonstrated that the provision of A. mellifera beehives may boost the production of bittergourd, buckwheat, and mustard crops in Nepal, three important cultivated plants to the local economy to growers and beekeepers [13]. As suggested by other studies, the yields of three crops evaluated here, bittergourd [43], buckwheat [41], and mustard [13, 41], benefit greatly from insect pollination. Moreover, the exact behavior of these insects on flowers is not clear. Therefore, further investigations could evaluate some ecological and behavioral features of these organisms that most likely are promoting pollination of these crops. Finally, the optimal number of beehives per hectare could be additionally investigated.

\section{Conclusions}

In summary, the crops evaluated here may be benefited by supplementation with honeybee hives. Our data showed that if only managed honeybees are present during blossom of target crops, the gains are considerable as compared with no insect access. For example, by adding honeybee hives, the productivity of the bittergourd (Momordica charantia) may increase around more than fourteen times (2.17 to 31.61 tons/ha), whereas that of buckwheat (Fagopyrum esculentum) may be raised by around more than two-fold (3.38 to 9.08 quintal/ha). For mustard (Brassica campestris), the seed production may be increased by around $43 \%$ (5.52 to 7.90 quintal/ha).

However, two relevant aspects need to be raised. First, the combined effect of wild insect community with added honeybee hives was not tested. Therefore, we cannot confirm whether supplementation of wild pollination services with honeybee hives is enough to, alone, increase crop yields to their maximum potential. Our analysis also indicates that free access by wild insects had an elevated and positive effect on productivity of three crops. Second, we acknowledge that the scenario of keeping honeybee colonies within caged enclosures and excluding wild pollinators is entirely unrealistic and is not suggested as a management strategy. We used this approach here to separately evaluate the effect of high densities of $A$. mellifera alone and compare them to natural pollinator services. Further works are needed to be conducted to understand the real-world dynamics of wild insect communities that are supplemented with managed honeybees and how this impacts yield overall.

\section{Data Availability}

Data can be provided on request.

\section{Conflicts of Interest}

The authors declare no conflicts of interest.

\section{Authors' Contributions}

Kedar Devkota conducted field surveys, data collection, and data entering. Charles F. dos Santos organized the dataset and carried out the statistical analysis. Prashant Rijal contributed to conducted field surveys. All the authors contributed to conceptual development of this work. All the authors wrote the original draft, discussed the main topics, and reviewed the manuscript.

\section{Acknowledgments}

The authors would like to thank their colleagues from the School of Health and Life Sciences at PUCRS for their continuous support. KD would like to thank the farmers who provided the bittergourd, buckwheat, and mustard crop fields and helped arrange other required activities. CFS thanks the Coordination for the Improvement of Higher Education Personnel (CAPES) of the Ministry of Education (MEC) for funding the Ph.D. of the first author and a postdoctoral fellowship from the National Postdoctoral Program (PNPD, Finance CODE 88882.314829/2019-01) for funding the second author.

\section{References}

[1] A.-M. Klein, B. E. Vaissière, J. H. Cane et al., "Importance of pollinators in changing landscapes for world crops," Proceedings of the Royal Society B: Biological Sciences, vol. 274, no. 1608, pp. 303-313, 2007.

[2] J. Ollerton, R. Winfree, and S. Tarrant, "How many flowering plants are pollinated by animals?" Oikos, vol. 120, no. 3, pp. 321-326, 2011.

[3] L. A. Garibaldi, I. Steffan-Dewenter, R. Winfree et al., "Wild pollinators enhance fruit set of crops regardless of honey bee abundance," Science, vol. 339, no. 6127, pp. 1608-1611, 2013.

[4] P. G. Willmer, H. Cunnold, and G. Ballantyne, "Insights from measuring pollen deposition: quantifying the pre-eminence of bees as flower visitors and effective pollinators," ArthropodPlant Interactions, vol. 11, no. 3, pp. 411-425, 2017.

[5] R. C. Sihag, "Bee diversity for floral diversity," Journal of Nature Science and Sustainable Technology, vol. 6, no. 4, pp. 271-276, 2012.

[6] S. G. Potts, J. C. Biesmeijer, C. Kremen, P. Neumann, O. Schweiger, and W. E. Kunin, "Global pollinator declines: trends, impacts and drivers," Trends in Ecology \& Evolution, vol. 25, no. 6, pp. 345-353, 2010.

[7] S. G. Potts, V. L. Imperatriz-Fonseca, and H. T. Ngo, The Assessment Report of the Intergovernmental Science-Policy Platform on Biodiversity and Ecosystem Services on Pollinators, Pollination and Food Production, IPBES, Bonn, Germany, 2016.

[8] J. Ollerton, "Pollinator diversity: distribution, ecological function, and conservation," Annual Review of Ecology Evolution and Systematics, vol. 48, no. 1, pp. 353-376, 2017.

[9] I. Bartomeus, S. G. Potts, I. Steffan-Dewenter et al., "Contribution of insect pollinators to crop yield and quality varies with agricultural intensification," PeerJ, vol. 2, Article ID e328, 2014.

[10] T. D. Breeze, B. E. Vaissière, R. Bommarco et al., "Agricultural policies exacerbate honeybee pollination service supply-demand mismatches across Europe," PLoS One, vol. 9, no. 1, Article ID e82996, 2014.

[11] A. Aebi, B. E. Vaissière, D. vanEngelsdorp, K. S. Delaplane, D. W. Roubik, and P. Neumann, "Back to the future: Apis versus non-Apis pollination-a response to Ollerton et al," Trends in Ecology \& Evolution, vol. 27, no. 3, pp. 142-143, 2012. 
[12] D. Kleijn, R. Winfree, I. Bartomeus et al., "Delivery of crop pollination services is an insufficient argument for wild pollinator conservation," Nature Communications, vol. 6, no. 1, Article ID 7414, 2015.

[13] K. Devkota, S. C. Dhakal, and R. B. Thapa, "Economics of beekeeping as pollination management practices adopted by farmers in Chitwan district of Nepal," Agriculture \& Food Security, vol. 5, no. 1, Article ID 6, 2016.

[14] S. Pokhrel and R. B. Thapa, "Effect of insect pollination on bitter gourd production in Chitwan, Nepal," Journal of Environment, vol. 11, 2019.

[15] L. N. Aryal, R. B. Thapa, S. Tiwari, and N. K. Chaudhary, "Monitoring of flower visiting insects on buckwheat (Fagopyrum esculentum Moench.) in Chitwan, Nepal," International Journal of Applied Sciences and Biotechnology, vol. 4, no. 3, pp. 380-385, 2016.

[16] B. E. Vaissiere, B. Freitas, and B. Gemill-Herren, Protocol to Detect and Assess Pollination Deficits in Crops: A Handbook for its Use, Food and Agriculture Organization of the United Nations, Rome, Italy, 2011.

[17] T. Toler, E. Evans, and V. J. Tepedino, "Pan-trapping for bees (Hymenoptera: apiformes) in Utah's West Desert: the importance of color diversity," Pan-Pacific Entomologist, vol. 81, pp. 103-113, 2005.

[18] J. W. Campbell and J. L. Hanula, "Efficiency of Malaise traps and colored pan traps for collecting flower visiting insects from three forested ecosystems," Journal of Insect Conservation, vol. 11, no. 4, pp. 399-408, 2007.

[19] J. Fox and S. Weisberg, An R Companion to Applied Regression, SAGE Publications, Third edition, Thousand Oaks, CA, USA, 2019, https://socialsciences.mcmaster.ca/jfox/ Books/Companion.

[20] T. Hothorn, F. Bretz, and P. Westfall, "Simultaneous inference in general parametric models," Biometrical Journal, vol. 50, no. 3, pp. 346-363, 2008.

[21] R. Ihaka and R. Gentleman, "R: a language for data analysis and graphics," Journal of Computational \& Graphical Statistics, vol. 5, no. 3, Article ID 299, 1996.

[22] R Development Core Team, A Language and Environment for Statistical Computing: Reference Index, R Foundation for Statistical Computing, 2018, https://www.r-project.org/.

[23] O. Rollin and L. A. Garibaldi, "Impacts of honeybee density on crop yield: a meta-analysis," Journal of Applied Ecology, vol. 56, no. 5, pp. 1152-1163, 2019.

[24] T. H. Ricketts, J. Regetz, I. Steffan-Dewenter et al., "Landscape effects on crop pollination services: are there general patterns?" Ecology Letters, vol. 11, no. 5, pp. 499-515, 2008.

[25] L. A. Garibaldi, I. Steffan-Dewenter, C. Kremen et al., "Stability of pollination services decreases with isolation from natural areas despite honey bee visits," Ecology Letters, vol. 14, no. 10, pp. 1062-1072, 2011.

[26] J. Hipólito, D. Boscolo, and B. F. Viana, "Landscape and crop management strategies to conserve pollination services and increase yields in tropical coffee farms," Agriculture, Ecosystems \& Environment, vol. 256, pp. 218-225, 2018.

[27] D. P. Abrol, Pollination Biology: Biodiversity Conservation and Agricultural Production, Springer, Berlin, Germany, 2012.

[28] B. K. Klatt, A. Holzschuh, C. Westphal et al., "Bee pollination improves crop quality, shelf life and commercial value," Proceedings. Biological sciences, vol. 281, no. 1775, Article ID 20132440, 2014.

[29] M. P. D. Garratt, D. J. Coston, C. L. Truslove et al., "The identity of crop pollinators helps target conservation for improved ecosystem services," Biological Conservation, vol. 169, pp. 128-135, 2014.

[30] C. E. Aslan, C. T. Liang, B. Galindo, H. Kimberly, and W. Topete, "The role of honey bees as pollinators in natural areas," Natural Areas Journal, vol. 36, no. 4, pp. 478-488, 2016.

[31] R. Pudasaini, R. B. Thapa, N. K. Chaudhary, and S. Tiwari, "Insect pollinators' diversity of rapeseed (Brassica campestris var. Toria) in Chitwan, Nepal," Journal of the Institute of Agriculture and Animal Science, vol. 33, pp. 73-78, 2015.

[32] R. Chifflet, E. K. Klein, C. Lavigne et al., "Spatial scale of insect-mediated pollen dispersal in oilseed rape in an open agricultural landscape," Journal of Applied Ecology, vol. 48, no. 3, pp. 689-696, 2011.

[33] R. Rader, J. Reilly, I. Bartomeus, and R. Winfree, "Native bees buffer the negative impact of climate warming on honey bee pollination of watermelon crops," Global Change Biology, vol. 19, no. 10, pp. 3103-3110, 2013.

[34] R. Halinski, C. F. dos Santos, T. G. Kaehler, and B. Blochtein, "Influence of wild bee diversity on canola crop yields," Sociobiology, vol. 65, no. 4, Article ID 751, 2018.

[35] I. Bartomeus, V. Gagic, and R. Bommarco, "Pollinators, pests and soil properties interactively shape oilseed rape yield," Basic and Applied Ecology, vol. 16, no. 8, pp. 737-745, 2015.

[36] R. Rader, I. Bartomeus, L. A. Garibaldi et al., "Non-bee insects are important contributors to global crop pollination," Proceedings of the National Academy of Sciences, vol. 113, no. 1, pp. 146-151, 2016.

[37] T. P. M. Fijen, J. A. Scheper, B. Boekelo, I. Raemakers, and D. Kleijn, "Effects of landscape complexity on pollinators are moderated by pollinators' association with mass-flowering crops," Proceedings. Biological sciences, vol. 286, no. 1900, Article ID 20190387, 2019.

[38] L. A. Morandin and M. L. Winston, "Wild bee abundance and seed production in conventional, organic, and genetically modified canola," Ecological Applications, vol. 15, no. 3, pp. 871-881, 2005.

[39] V. Le Féon, F. Burel, R. Chifflet et al., "Solitary bee abundance and species richness in dynamic agricultural landscapes," Agriculture, Ecosystems \& Environment, vol. 166, pp. 94-101, 2013.

[40] S. A. M. Lindström, L. Herbertsson, M. Rundlöf, H. G. Smith, and R. Bommarco, "Large-scale pollination experiment demonstrates the importance of insect pollination in winter oilseed rape," Oecologia, vol. 180, no. 3, pp. 759-769, 2016.

[41] T. S. Woodcock, Pollination in the Agricultural Landscape: Best Management Practices for Crop Pollination, Canadian Pollination Initiative (NSERC-CANPOLIN), University of Guelph, Guelph, Canada, 2012.

[42] C. Scott-Dupree, G. Hergert, J. D. Nelson, B. Termer, and M. Winston, A Guide to Managing Bees for Crop Pollination, Canadian Association of Professional Apiculturalists, Vancouver, Canada, 1994.

[43] D. W. Roubik, The Pollination of Cultivated Plants a Compendium for Practitioners, Food and Agriculture Organization of the United Nations, Roma, Italy, 2018. 